\title{
A Decision Support System for Course Offering in Online Higher Education Institutes
}

\author{
Ahmad A. Kardan, Hamid Sadeghi \\ Advanced E-Learning Technologies Laboratory, Department of Computer Engineering and Information Technology, \\ Amirkabir University of Technology, Tehran, Iran \\ Corresponding Author's E-mail: hisadeghi@gmail.com
}

Received 29 June 2012

Accepted 18 February 2013

\begin{abstract}
Prior to every academic semester, every department's administrator is required to offer the best overall set of courses to meet student requirements, instructor needs and department regulations. The key contributions of this research is firstly, determining the potential factors that influence student behavior on the online courses they choose, secondly, modeling the course offering problem and fitting a function to a training set of data using neural network approach, thirdly, design and implementation of a decision support system to help the department's administrator to simulate student behavior in course selection process and support his/her decisions on the courses to be offered, and lastly, employing the proposed decision support system to perform what-if analysis and goal seeking behavior. The samples of the experiments came from 298 online graduate courses in 14 academic terms from 2005 to 2011 . The results revealed high prediction accuracy on the experimental data. The performance of the introduced decision support system was also compared with three well-known regression techniques, "support vector regression", "K-nearest neighborhood", "decision tree" and a traditional approach. The finding exposed that the suggested decision support system outperformed the others significantly.
\end{abstract}

Keywords: Decision Support system; E-learning; Neural networks; Course offering; Student course selection; What-if analysis; Goal seeking

\section{Introduction}

In today's world, every day we are faced with situations where we need to make a decision. It can be a minor and routine one such as choosing what to make for dinner or what to wear for work. At the other extreme, sometimes we are required to make major and difficult decisions which have large, longterm consequences and can alter the course of our life path such as academic major or career choice. Due to the complex nature of these kinds of problems, it is a difficult task for an individual to select the best alternative from the existing solutions. Modern computerized systems have capabilities that can facilitate human decision making in a number of ways, including; speedy computations, improved communication and collaboration, increased productivity of group members, improved data management, overcoming cognitive limits in processing and storing information, quality support, agility support, using the Web, and also anywhere and anytime support ${ }^{4}$. 
In all online universities around the world, prior to every academic semester, administrators in academic departments are required to make some crucial decisions for optimum course offering. They need to estimate the approximate number of students who are interested in taking every offered course. This number can help them to decide which courses are more appropriate to be run, which instructor is well suited to a specific course, what times are more proper for a particular course, and so on. It should be noted that an administrator might not offer all program courses due to some restrictions, including lack of sufficient department resources (e.g., faculty unavailability or technical constraints) and overheads of running too many courses. Thus, the central problem in online higher education institutes is to choose the best overall set of courses to satisfy student needs considering the existing restrictions. The course selections the students make create a chain of reactions that influence future course choices, skill development, and job decisions ${ }^{3}$. Failing to consider this issue may lead to inefficient resource usage and consequently student dissatisfaction. According to Sun et al. ${ }^{44}$ course selection has a strong association with learner satisfaction which is one of the essential indicators of the quality of an e-learning system ${ }^{7,30,50}$. High degree of student satisfaction leads to an increase in student enrollments and motivation, lower attrition rates, and a more productive learning environment $9,11,16,27,34,42$. It was also reported that student satisfaction with a course is a key factor that influences their decisions to continue or drop-out of the course ${ }^{1,12,32}$. The course offering problem in the context of education is a major one and needs considerable attention. The problem is categorized as a complex and unstructured one for which no routine and standard solution methods exist. It is a multivariate nonlinear problem and depends on many factors $1,2,3,38,39,46$. The factors influencing an administrator's decision to offer a course are discussed in more detail in the next sections.

In 1971, Gorry and Scott-Morton ${ }^{21}$ first articulated the major concept of the Decision Support System (DSS). Those authors defined DSS as "Interactive computer-based systems, which help decision makers utilize data and models to solve unstructured problems". DSS are computer-based technologies which intend to extend decision makers' capabilities while not replacing their judgment. They are aimed at decisions in which judgment is required or at decisions that cannot be completely supported by algorithms ${ }^{47}$. Recently, in the literature, DSS technology has been successfully applied to numerous decision-making problems in many disciplines, including traditional and online education $24,26,29,33,51$. However, there has been no report on applying DSS to the course offering problem. Hence, the major objective of this study is firstly identifying the potential factors that influence student behavior on the online courses they select, secondly, modeling the course offering problem and fitting a function to the training data through neural network approach, thirdly, design and implementation of a DSS to help a department administrator simulate student behavior in course selection process and predict the number of registrations in every course, and lastly, using the suggested DSS to perform a what-if analysis and goal seeking behavior.

\section{ELCAUT: An Online Graduate College}

In this section an online graduate college called ELCAUT is introduced. The data used to design and implement the suggested DSS came from some courses from the above mentioned college. ELCAUT stands for "E-Learning Center of Amirkabir University of Technology" and was established in 2000 as the first e-learning center for higher education in Iran. ELCAUT currently offers 24 different master's programs in 9 colleges. All courses are delivered via live synchronous online sessions through a virtual classroom tool. This technology allows an instructor to lecture while students can ask questions, interact with other students and even give presentations. In this study, a master's program called "Information Technology and Management Engineering" was considered as the case study. More explanations about the dataset are provided in the next sections.

ELCAUT, similar to most universities in the world, conducts online surveys at the end of each academic term to discover how much students are satisfied with courses, instructors, and technical aspects of the Learning Management System (LMS). Within each of the courses a student is taking, online questionnaires for course and instructor satisfaction are provided. The evaluations begin three weeks before the end of semester and end the last week of 
class. The data gathered through this evaluation is used by instructors as feedback for improvement of their courses. Moreover, this data is presented to the college administrators to improve the student and educational affairs. Technical experts also employ some required data to improve and extend the LMS. This online survey can shorten and automate the process of analyzing data and comparing results for different courses and instructors. It can automatically calculate basic statistical data such as the mean, mode and standard deviation. It can also generate a database for each questionnaire which can be utilized for more complex statistical operations.

\section{The Components of the DSS Model}

A number of different factors can be influential in modeling student behavior to take a specific course in the forthcoming academic term. The trained model can then help an administrator by simulating student behavior in course selection process and determining their most satisfying courses for the upcoming semester. A DSS model is made up of four rudimentary components including decision variables, uncontrollable variables, intermediate result variables, and result or outcome variables. Decision variables are controlled by decision makers and describe alternative choices. Uncontrollable variables are those environmental factors which influence the result of decisions but are outside of decision maker's control. These two kinds of variables are considered independent ones. Intermediate result variables reflect intermediate outcomes in the model. Also, result variables denote the degree of efficacy of a system and indicate how well the system performs or achieves its goals. Obviously, the two latter variables are dependent on the two former ones. The modeling process involves identifying the variables and relationships among them. Finally, the values of the result variables are determined by solving the model.

It is interesting to note that students decide to select or cancel a particular course using the information obtained through a wide variety of sources. They include academic advisors, course descriptions, course syllabus, college bulletin ${ }^{4}$, profiles of the instructors, online discussion forums, informal word of mouth, online rating services ${ }^{15,43}$, and evaluation of the course before the drop and add period. Since the mentioned data is not available to be fed into the model, other similar data described in the following is used instead.

\subsection{Uncontrollable variables}

In this section seven various uncontrollable variables are introduced. They cannot be controlled by an administrator but their values are measureable. The first three variables are associated with the level of student satisfaction with the course. The required data to calculate their values can also be extracted from the online questionnaires filled by the students who took the course in the previous semester. ELCAUT, like most universities in the world, carries out online surveys using online questionnaires at the end of each semester, testing the student satisfaction with courses and instructors. Every questionnaire consists of some questions asking the degree of agreement on the given sentences using a Likert scale of 1 to 5 , in which 1 represents strong disagreement and 5 denotes strong agreement. The questions of the questionnaire are categorized into the three groups which appraise a course in different aspects including course characteristics, instructor characteristics and student workload. Since the importance degree of each sentence in the questionnaire might differ from one another based on the student perspective for the course selection, a weight is assigned to each sentence. In order to obtain the weights, an online survey was conducted and students were asked to state their opinion regarding the influence of each factor on selecting a course. The response to each sentence was on the Likert scale ranging from 1 (not at all important) to 5 (very important). A total of 214 students participated in the survey. The mean of results for each sentence were then computed and normalized between 0 and 1 . The obtained weights are reported in tables 1,2 and 3.

\subsubsection{Course score}

Typically, students like to take interesting and useful courses. According to Babad ${ }^{3}$, one of the vital factors in selecting a specific course by students is the characteristics of the course. McGoldrick and Schuhmann ${ }^{39}$, over a sample of 400 undergraduate students, exposed that course selection is more of a function of relevance to future career and perceived interest in the course topic. As mentioned earlier, an online questionnaire is formally administered to all students in all virtual classes at the end of each 
semester in ELCAUT. It consists of a series of statements to which the student is expected to respond on a five-point scale from strongly agree to strongly disagree. In addition, each sentence is associated with a weight indicating its importance degree. Table 1 represents the factors related to the course characteristics extracted from the questionnaire and their weights.

Table 1. Course characteristics

\begin{tabular}{|c|c|c|}
\hline No. & Statement in questionnaire & Weight \\
\hline 1 & The course can contribute to my personal development & 0.294 \\
\hline 2 & The course helps me for present work or prepare me for future occupation & 0.825 \\
\hline 3 & The course subject is interesting & 0.703 \\
\hline 4 & The course is useful in giving new knowledge or skills & 0.683 \\
\hline 5 & The course helps to change my attitude to life & 0.316 \\
\hline 6 & The course covers modern topics in the program & 0.719 \\
\hline
\end{tabular}

The score of each course is the arithmetic mean of the weighted average of the student responses to the questionnaire in the last semester the course was offered. It is computed as:

Course Score $=\frac{1}{\sum_{k=1}^{L} M_{k}}\left(\sum_{k=1}^{L} \sum_{j=1}^{M_{k}} \frac{\sum_{i=1}^{N} W_{i} C_{k j i}}{\sum_{i=1}^{N} W_{i}}\right)$ where $W_{i}$ implies the weight of $i^{\text {th }}$ question in the questionnaire, $C_{k j i}$ denotes the response of $j^{\text {th }}$ student to $i^{\text {th }}$ question in the $k^{\text {th }}$ online class, $N$ is the number of weights which here equals $6, M_{k}$ is the number of students in the $k^{t h}$ virtual class, and $L$ implies the number of online classes offering the course. As can be seen, this score is used as the indicator of the course characteristics without considering its instructor.

Table 2. Instructor's characteristics

\begin{tabular}{clc}
\hline No. & \multicolumn{1}{c}{ Statement in questionnaire } & Weight \\
\hline 1 & The instructor starts online classes promptly & 0.213 \\
2 & $\begin{array}{l}\text { The instructor encourages students to participate in online class by questioning, presentation, } \\
\text { discussion, project, etc. }\end{array}$ & 0.466 \\
3 & The course materials are placed on line in a timely fashion & 0.529 \\
4 & The instructor has good rapport with the students & 0.765 \\
5 & The instructor is easily and fast accessible outside the online classroom via communication & 0.657 \\
6 & facilities (e.g., chat, e-mail, and discussion forum) & 0.781 \\
7 & The grading policy of the course is objective and impartial & 0.624 \\
8 & The course materials are prepared well in an appropriate format & 0.811 \\
9 & The language used for delivering instruction is clear and understandable & 0.388 \\
10 & the course & The course time is used effectively \\
11 & The instructor helps students to develop self confidence & 0.387 \\
12 & The instructor shares innovations about the course content with students & 0.413 \\
13 & The instructor is a known expert on this topic & 0.743 \\
14 & The provided assignments are interesting & 0.830 \\
15 & The instructor motivates the students to work hard & 0.551 \\
16 & The instructor respects the student personality and capabilities & 0.378 \\
17 & Students are given fast and helpful feedback on the course activities such as assignments, \\
18 & presentation, discussion and etc. & The instructor fosters cooperative learning (e.g., by group activities, discussions etc.) \\
19 & The instructor handles the e-learning environment effectively & 0.647 \\
20 & The instructor is enough knowledgeable about the course & 0.735 \\
\hline
\end{tabular}




\subsubsection{Instructor's score}

Several studies exposed that students are drawn to the courses that have effective instructors ${ }^{2,17,31,40}$. All those researchers disclosed that instructor characteristics contribute positively to student satisfaction with the course. Data regarding the overall satisfaction of the instructor are taken through the online survey. The factors associated with the instructor derived from the questionnaire of ELCAUT are reported in table 2. Note that the student ratings of an instructor for various courses may differ from one another. For instance, an instructor may be a famous expert on the topic of a particular course but not on the topics of other courses. After extracting the required information from the questionnaires, the mean of weighted average of the instructor's characteristics in all online classes from the last term the course was taught by that instructor is employed as the value of this variable.

\subsubsection{Student's workload}

Entwistle and Ramsden ${ }^{18}$ defined student workload as the pressure placed on students in terms of demands of the syllabus and assessment tasks. Prior to every term, students might be apprehensive of those courses which are considered too difficult. Marsh and Roche ${ }^{38}$ analyzed a large database of 5,433 classes and found an important factor that influences student decisions to take a course to be the workload they are asked or expected to do. Moreover, Centra ${ }^{10}$ discovered that the courses which are difficult or too elementary have low student ratings and the courses that are considered in between or "just right" receive the highest ratings. The factors utilized in the questionnaire of ELCAUT associated with the student workload in a course are listed in table 3 . The mean of the weighted average of student workload in all the online classes from the last semester the course was taught by the instructor is used as the value of this variable.

Table 3. The factors corresponding to the student's workload

\begin{tabular}{|c|c|c|}
\hline No. & Statement in questionnaire & Weight \\
\hline 1 & The course contents are difficult to understand & 0.710 \\
\hline 2 & The number of topics to be covered is large & 0.735 \\
\hline 3 & The tempo of the course progress is fast & 0.763 \\
\hline 4 & The frequency of quizzes is high & 0.827 \\
\hline 5 & It is tough to get high grades in the exams and quizzes & 0.850 \\
\hline 6 & The number of assignments is large & 0.881 \\
\hline 7 & The assignments of the course are difficult & 0.749 \\
\hline 8 & Attendance in the course is required & 0.604 \\
\hline
\end{tabular}

\subsubsection{Instructor's grade}

Sometimes, grades, rather than learning, become the primary goal of students. They might need to earn high grades for future admission into advanced programs, applying for a well-paying job, or for any other personal reason. Greenwald and Gillmore ${ }^{20}$ found that the instructors who give higher grades were better liked. Also, Svanum and Aigner 46 revealed that course grades have a moderately strong effect on student ratings of the course in an online university. According to Babcock 5, students significantly tend to enroll in those courses which are taught by lenient instructors. Therefore, the mean of grades of a course in the previous semester is a major criterion that students usually take into account for selecting the course. Sometimes an instructor teaches a particular course for the first time at the university. Since in this case the corresponding grades are not available, the mean of grades given by the instructor in other courses taught in the preceding semester can be utilized instead. This technique can be applied to the two previous variables as well.

\subsubsection{Course type}

Just like in a traditional college or university, every online program has a set of required and elective course offerings. Required courses are those that must be taken to fulfill specific requirements of the program. Elective courses are those selected as supplemental to the list of required courses on the basis of personal interest, abilities, and career goals. In most higher education institutes, required courses usually have lower degrees of freedom in selection 
than the elective ones. Previous studies reported that students rate elective courses more favorably than required ones, presumably because students are participating in a course that they have an interest or focus in ${ }^{6,14}$. Hence, course type is another uncontrollable variable that needs to be considered for modeling the student course selection process.

\subsubsection{Number of eligible students}

Eligible students are those who are allowed into the course, such as students who have not previously passed the course and those who have met the prerequisites and have their advisor's permission. It is clear that the larger the number of eligible students for a particular course in the program, the greater the demands for the course.

\subsubsection{Number of guest students}

Guest/visiting students are those who are matriculated at a program but are interested in taking one or more courses at another program. It is a rational behavior which leads fascinating courses to usually have some guest students every semester. In order to take these kinds of demands into consideration, the mean of numbers of all the guest students taken a course in the two preceding terms is calculated. The result is added to the predicted number of students who are interested in taking the course which is determined by the model.

\subsection{Decision variables}

\subsubsection{Course}

Prior to every semester, an administrator is free to decide which courses should be run. However, he/she must take the department regulations into account when choosing a course. For instance he/she is not allowed to offer a course which is not in the program. Also, sometimes a course is going to be offered for the first time and therefore, no corresponding student ratings from the preceding terms are available to compute its score. In this case, the administrator is responsible for assigning a score to the course. $\mathrm{He} / \mathrm{she}$ might either use only his/her expertise to determine the score or consult with expert instructors to vote for the course or employ the mean of student ratings of all the other courses offered in the previous term. In this study the last approach was utilized. In addition, the administrator is responsible to resolve how many courses should be offered for the upcoming term. Note that he/she might not offer all department courses due to some restrictions, including lack of sufficient resources (e.g., faculty unavailability or technical constraints) and overheads of running too many courses. Another administrator duty is to assign a number of guest students to each first-time offered course. In order to determine this number, he/she might either utilize only his/her experience, inquire of other specialists, or apply the average of total guest students of all courses offered in the preceding semester. In the present work the last approach was put to use.

\subsubsection{Instructor}

Before every academic term, instructors announce a set of their interesting courses for teaching to the administrator of the department. However, an administrator is not naturally able to alter an instructor's characteristics and hence, as mentioned earlier, the instructor's score is considered an uncontrollable variable. However, the administrator can decide which instructor is more appropriate for a particular course. Moreover, he/she may occasionally determine that there is no any suitable instructor for a specific course in the department and then invite a new one. In this case that the instructor is a newcomer to the department and no information is available about him/her, the administrator may either borrow the instructor's former data (i.e. instructor's score, student workload and instructor's grade), if it is available, from the source department or consider the mean of data of all the instructors taught in the previous semester to calculate the values of the instructor's uncontrollable variables. In this work the second approach was used.

\subsubsection{Course time}

McGoldrick and Schuhmann ${ }^{39}$, in a large scale study revealed that college student choice of courses is in large part a function of the time of day the course is offered. Those authors found that students are obviously averse to early morning and late afternoon class times, with the former least preferred. Furthermore, their study disclosed while both late morning and early afternoon classes are statistically greatly preferred to either early morning or late afternoon class times, students place the greatest value on late morning class times. Thus, the course 
time as another decision variable, accepts 4 values including early morning, late morning, early afternoon, and late afternoon.

\subsubsection{Number of time conflicts}

Online classes which are overlapping in time cannot be attended by the same students. Without taking this issue into consideration, a schedule very likely incurs time conflicts, preventing lots of students from taking their intended courses. Hence, the number of time conflicts is another decision variable that might influence a student's decision to take a course. Administrators, for better time conflict detection, can categorize all the program's courses into several groups. Each group includes those courses which cannot cause overlapping. For example, a unique course may be taught by several instructors, but every student can only choose one of them. Thus, it would be better to classify these courses under one group. Another instance is courses which are prerequisites for other courses. Obviously, selection of two different courses from distinct groups occurring in the same time interval might cause a time conflict.

\subsubsection{Final examination time}

One of the other major factors influencing a student's decision to take a course is the final examination time assigned to the course. Actually, if the time between exams is lengthened in hopes of producing more time to study and fewer conflicts, then students are able to take their favorite courses. Otherwise they may avoid selecting some courses with inappropriate final examination time. The value of this decision variable is the weighted average of the exams happening in the past 3 days of the exam for a particular course $K$, called $E_{k}$, computed as

$$
E_{k}=\frac{1}{4} \sum_{i=1}^{4} \frac{1}{i} x_{i}
$$

where $x_{i}$ implies the number of exams occurring in the $i^{\text {th }}$ previous day. For example, $x_{1}$ is number of exams that take place in the exam day of course $K$.

\subsection{Result variable}

The model has only one result variable which depends on the uncontrollable and decision variables.
It is the predicted number of registrations in the course after the drop and add period in the coming semester.

\section{Construction of the Model}

\subsection{Data collection and preprocessing}

The present study was applied on a master's program called, "Information Technology and Management Engineering," offered by ELCAUT. The program consists of 6 required and 9 elective courses. Students are required to take and pass 4 out of 9 elective courses and also 4 out of 6 required courses during their program. The samples collected for this research included 298 courses over 14 academic terms from 2005 to 2011 . The maximum capacity of each virtual class is 30 , and the classes with less than 10 students enrolled are canceled in accordance with the department guidelines. Further details about the total number of virtual classes and students enrolled in the program from the fall 2005 to the spring 2011 semesters are reported in table 4.

It is important to note that students in the course selection process try to choose the most satisfying courses among the ones offered. In other words, they compare the offered courses in various aspects such as course characteristics, instructor characteristics, student workload, instructor grades, course type, course time, and final examination time. In order to imitate this student behavior, a z-score for each mentioned facet of a course is calculated. A z-score (also known as z-value, or standard score) is a measure of the divergence of an individual experimental result from the most probable result, the mean. Indeed, it denotes how many standard deviations an observation is above or below the mean. The $\mathrm{z}$-score of course $i$ in the last term it was offered is computed as

$$
z \operatorname{score}\left(x_{i}\right)=\frac{x_{i}-\mu}{\delta}
$$

where $x_{i}$ represents the value of a specific feature of course $i$ to be standardized. Also, $\mu$ and $\delta$ indicate the mean and standard deviation of all the values in the forthcoming semester, respectively. 
Table 4. The number of online classes and students in each term

\begin{tabular}{clcc}
\hline No. & Semester & No. of online classes & No. of registered students \\
\hline 1 & Fall 2005 & 21 & 161 \\
2 & Spring 2005 & 19 & 146 \\
3 & Fall 2006 & 22 & 177 \\
4 & Spring 2006 & 20 & 156 \\
5 & Fall 2007 & 23 & 184 \\
6 & Spring 2007 & 20 & 158 \\
7 & Fall 2008 & 21 & 160 \\
8 & Spring 2008 & 20 & 152 \\
9 & Fall 2009 & 22 & 175 \\
10 & Spring 2009 & 21 & 169 \\
11 & Fall 2010 & 23 & 191 \\
12 & Spring 2010 & 21 & 172 \\
13 & Fall 2011 & 23 & 189 \\
14 & Spring 2011 & 22 & 183 \\
\hline
\end{tabular}

\subsection{Training the model}

Artificial neural network techniques are widely utilized as powerful tools in dealing with modeling nonlinear behaviors in a large number of areas including traditional and online education $8,19,28,29,35,36,48$. They enable the construction of models that efficiently describe real world systems. In this work, a feed-forward three-layer perceptron network was utilized. Previous researches revealed that this kind of network architecture is technically suffice for achieving satisfactory approximation ${ }^{25,49}$. The input layer has 8 nodes including: the course score, the instructor's score, student workload, instructor's grade, course type, course time, number of time conflicts, and final examination time. However, the first three include several sub-factors. But, note that considering each sub-factor as an individual one may result in increasing the number of network inputs thereby over-fitting or memorization of the training data set and a reduced ability of the network to generalize and predict accurately. The values of the variables must be standardized by $\mathrm{z}$-score transformation before application to the network as well.

The data set was divided into three separate sets. Namely, the training, validation, and test set. The training set comprised 209 courses offered in the fall of 2005 to spring 2009 semesters. The validation set, which was used to avoid over-fitting phenomenon, consisted of 44 courses in the fall of 2010 and spring 2010 semesters. The remaining data from 45 courses, offered in the fall of 2011 and spring 2011 terms, was utilized as the test set.

The number of nodes in the hidden layer is an important factor of a successful training and depends on several factors including the size of the training data set, complexity of the problem, number of nodes in both the input and output layers, network architecture, training algorithm, amount of noise in the actual output, and the required accuracy of the prediction ${ }^{45}$. It is interesting to note that having too few hidden nodes may lead to a reduction of the learning ability of a network, whereas too many hidden nodes may result in over-fitting phenomenon 45 . No universal rule exists for selecting the number of nodes in the hidden layer even though some simple rules of thumb have been suggested ${ }^{41}$. Thus the practitioner's strategy of running a number of experiments ${ }^{13}$ is used to determine the selection of the number of nodes for the hidden layer. This research employed 20 nodes in the hidden layer of the network. The output layer has one node and generates a value between 0 and 1 . This value is a prediction of the proportion of student course registrations after the drop and add period to the number of eligible students in the program for the upcoming term. This output is then multiplied by the number of eligible students for the course and finally added to the mean of numbers of all the guest students that have taken the course in the two previous semesters.

The network was developed using MATLAB $^{\circledR}$ R2010b neural network toolbox. Training algorithm 
was Levenberg-Marquardt ${ }^{37}$, which has been exposed to increase the speed convergence and efficacy of the moderate-sized network training ${ }^{22,23}$. The transfer functions for hidden and output layers were chosen as log-sigmoid and linear, respectively. During the training phase, the network weights and neuron biases were adjusted based only on the training set, and the performance of the network was assessed by computing the mean squared error (MSE) between its targets (desired responses) and outputs (network responses). In the course of the experiment, 30 training iterations took place and the best trained network was kept. Figure 1 demonstrates the performance of the network.

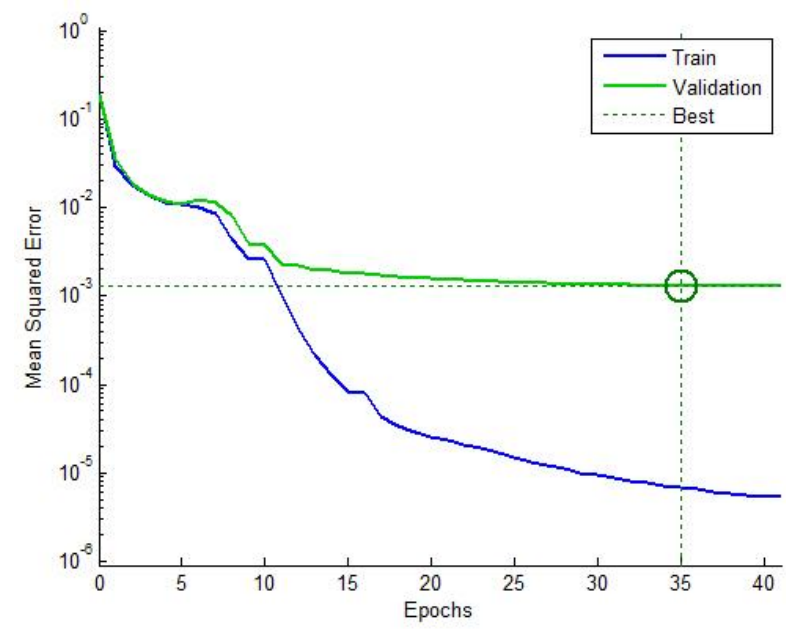

Fig. 1. Performance of the training and validation data sets in terms of MSE

As shown in the figure the network was efficient in minimizing the performance criterion (MSE) between targets and outputs. The figure also reports that the best validation performance was 0.0013 at epoch 35. After this point the network performance deteriorated and over-fitting occurred. Finally, the training stopped at epoch 41, indicating quick learning, and the parameters of the best previously trained network were stored. Moreover, in order to better interpret the observed errors, another graph was plotted. As shown in figure 2, the graph implies the percentage of incorrect predictions for the number of students that take a course. For instance, the figure reports that the trained model was unsuccessful in prediction of $2.34 \%$ of student decisions at epoch 35 .

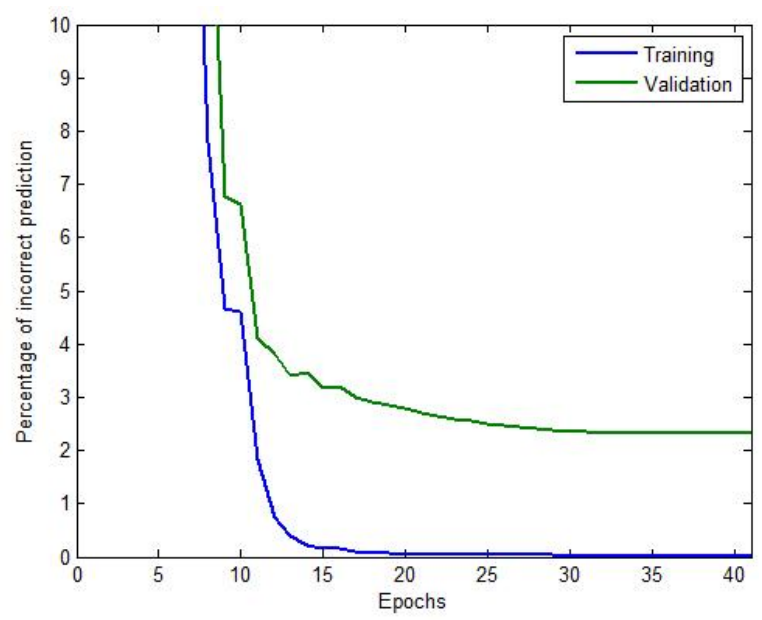

Fig. 2. Performance of the training and validation data sets in terms of percentage of incorrect prediction

In addition to MSE, another statistical indicator to appraise the performance of a model is correlation coefficient ( $\mathrm{R}$ value). It ranges from -1 to 1 and provides information on the strength of linear relationship between the observed and the calculated values. The higher the correlation coefficient, the stronger the relationship. Figure 3 and 4 give the linear regression between the targets and outputs on the training and validation samples, respectively. The best linear fit is denoted by a solid line, whereas the perfect fit (outputs exactly equal to targets) is represented by the dashed line. As the best linear fit line comes close to the perfect fit line, the neural network simulation is evaluated as superior. The correlation coefficient $(\mathrm{R})$ in figure 3 is equal to 0.998 and the best linear regression nearly overlaps the perfect linear fit which indicates a very strong correlation between the targets and outputs on the training data points. Figure 4 illustrates the correlation of 0.934 between the targets and outputs on the validation data set. As shown in the figure, the best linear fit line and the perfect fit line are very close to one another which implies a reasonably accurate fit.

Figure 4 demonstrates that more errors were made for the middle values, and less errors for small and large values. This can be interpreted as meaning that the results of prediction in case the model predicts the number of registrations as small or large, are more accurate than the case the model predicts the number as middle. 


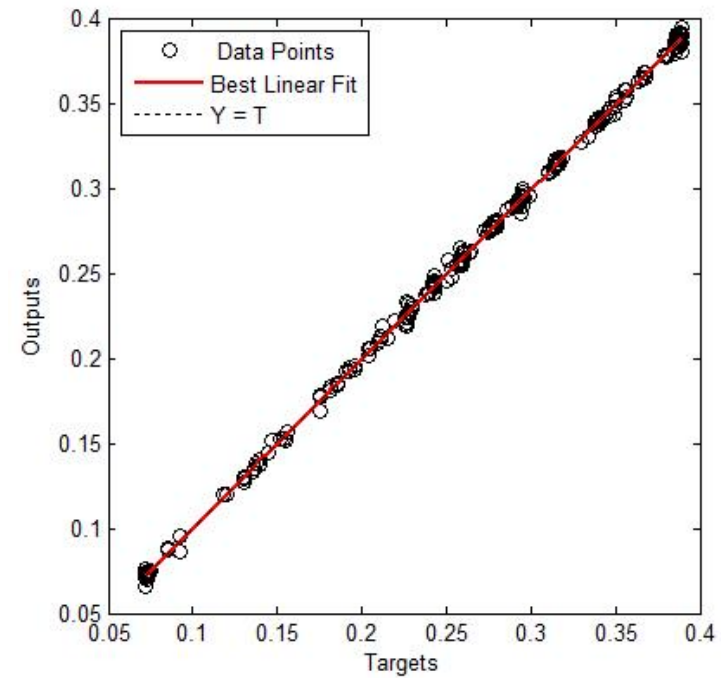

Fig. 3. Linear regression between the targets and outputs on the training data set, $\mathrm{R}=0.998$

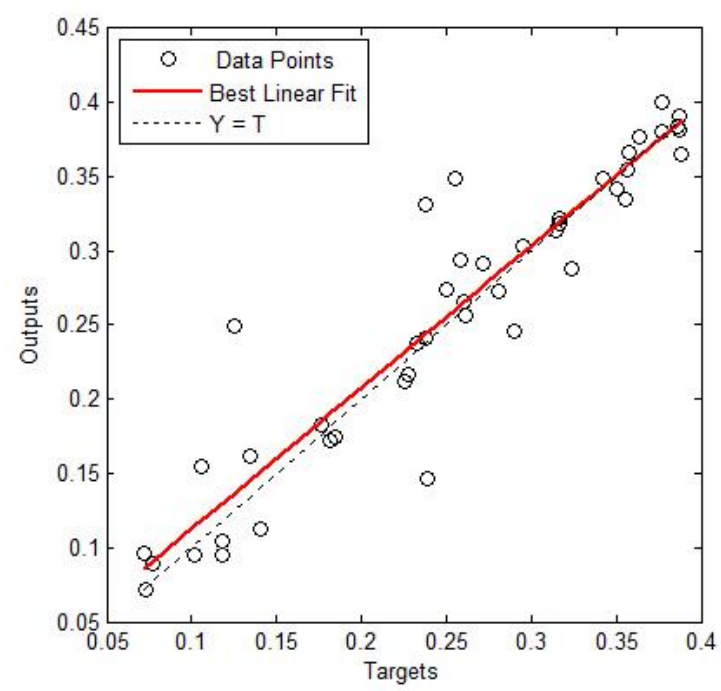

Fig. 4. Linear regression between the targets and outputs on the validation data set, $\mathrm{R}=0.934$

\subsection{Testing the model}

During the testing phase, an unseen data set corresponding with 45 courses in the fall 2011 and spring 2011 semesters was presented to the trained network to examine the prediction accuracy. The performance of the trained model was reflected by MSE and correlation coefficient measures. The model on the test data returned the MSE of 0.0014 and the correlation of 0.929 , indicating its high predictive ability. However its accuracy on the unseen data was slightly worse than on the training data. Figure 5 illustrates the absolute value of the difference between target and output for each test sample. In other words, this figure exposes the discrepancy between the observed and predicted number of students in each class. As figure shows the trained model correctly predicted 20 out of 45 test cases. However, the model in four cases 10, 19, 24 and 34 was not very successful. In the remaining cases the prediction errors were negligible. Figure 6 demonstrates the correlation of 0.929 between the simulation results of the neural network and the test data samples. The close proximity of the best linear fit to the perfect fit, as observed in the figure, reveals a good correlation among the network predictions and the experimental data.

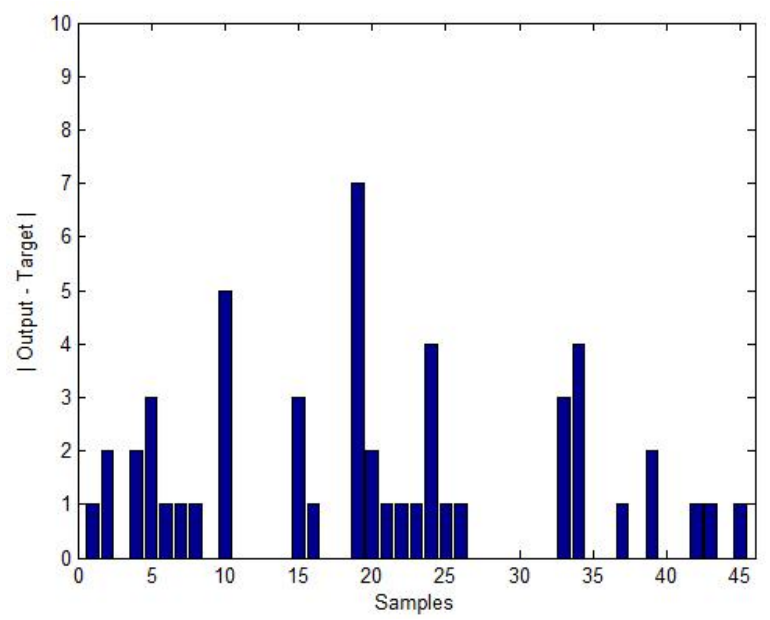

Fig. 5. Comparison between the targets and outputs on the test data set

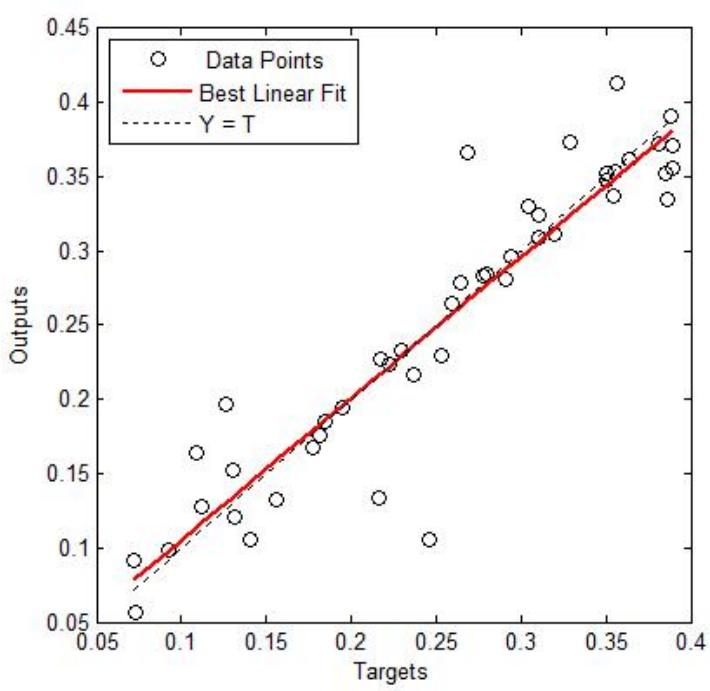

Fig. 6. Linear regression between the targets and outputs on the test data set, $\mathrm{R}=0.929$ 
To investigate the efficiency of the proposed neural network model, it was compared with one unintelligent approach and three other machine learning techniques. In the unintelligent method, the administrator simply applies a template of past student registration data to the upcoming semester. Hence, for each of the two last terms (the fall 2011 and spring 2011) the number of student registrations after the drop and add period in every course was compared to the corresponding one in the previous term. Moreover, three other regression methods called "support vector regression" (SVR), "K-nearest neighborhood" (KNN), and "decision tree" (DT) were utilized to model the problem. In each case several experiments were performed with different parameters and the best result was chosen as the outcome of the method. The performance of the models were measured using MSE and a correlation coefficient. Table 5 reports the results. For better comparison, the results of our suggested neural network model are also listed in the last row of the table.

Table 5. Comparison between the performance of different models

\begin{tabular}{lcc}
\hline Method & MSE & Correlation coefficient \\
\hline Template of past students' registration data & 0.0069 & 0.584 \\
Support vector regression model & 0.0042 & 0.844 \\
K-nearest neighborhood model & 0.0039 & 0.889 \\
Decision tree model & 0.0025 & 0.906 \\
Neural network model & 0.0014 & 0.929 \\
\hline
\end{tabular}

As reflected in the table, neural network model outperformed the others, followed by DT, KNN, and SVR models. Furthermore, the unintelligent method gave low performance in comparison to the other regression models. Obviously, the inefficiency of the unintelligent method is due to some differences between the terms. For example, changes in instructor characteristics and grading policy, student course workload, time conflicts between courses, and inappropriate classes or final examinations time over the academic semesters.

\section{Trial-and-Error Sensitivity Analysis}

The impact of changes in any variable, or in a number of variables, can be determined using a simple trial-and-error approach. When the changes are repeated several times, better and better solutions may be disclosed. Such experimentation, which is straightforward to conduct using the proposed model, has two approaches: what-if analysis and goal seeking.

\subsection{What-if analysis}

According to Turban et al. ${ }^{47}$ what-if-analysis, also called scenario analysis, is structured as "what will happen to the solution if an input variable, an assumption, or an uncontrollable variable value is changed?" In the course offering problem, an administrator can construct a series of scenarios (i.e., what-it cases) considering various situations and constrains, and observe the impact of the changes on the result variable. However, in addition to the uncontrollable variables mentioned earlier, the administrator's decisions are often limited by several unavoidable constraints such as department regulations and limited resources, program requirements and instructor time. Via a suitable user interface, it is easy for an administrator to ask the trained and ready-to-use model these types of questions and get immediate answers. To support the administrator's decisions, an interactive user interface was designed and implemented using MATLAB R2010b graphical user interface development environment (GUIDE). Figure 7 shows a screenshot of this tool. 


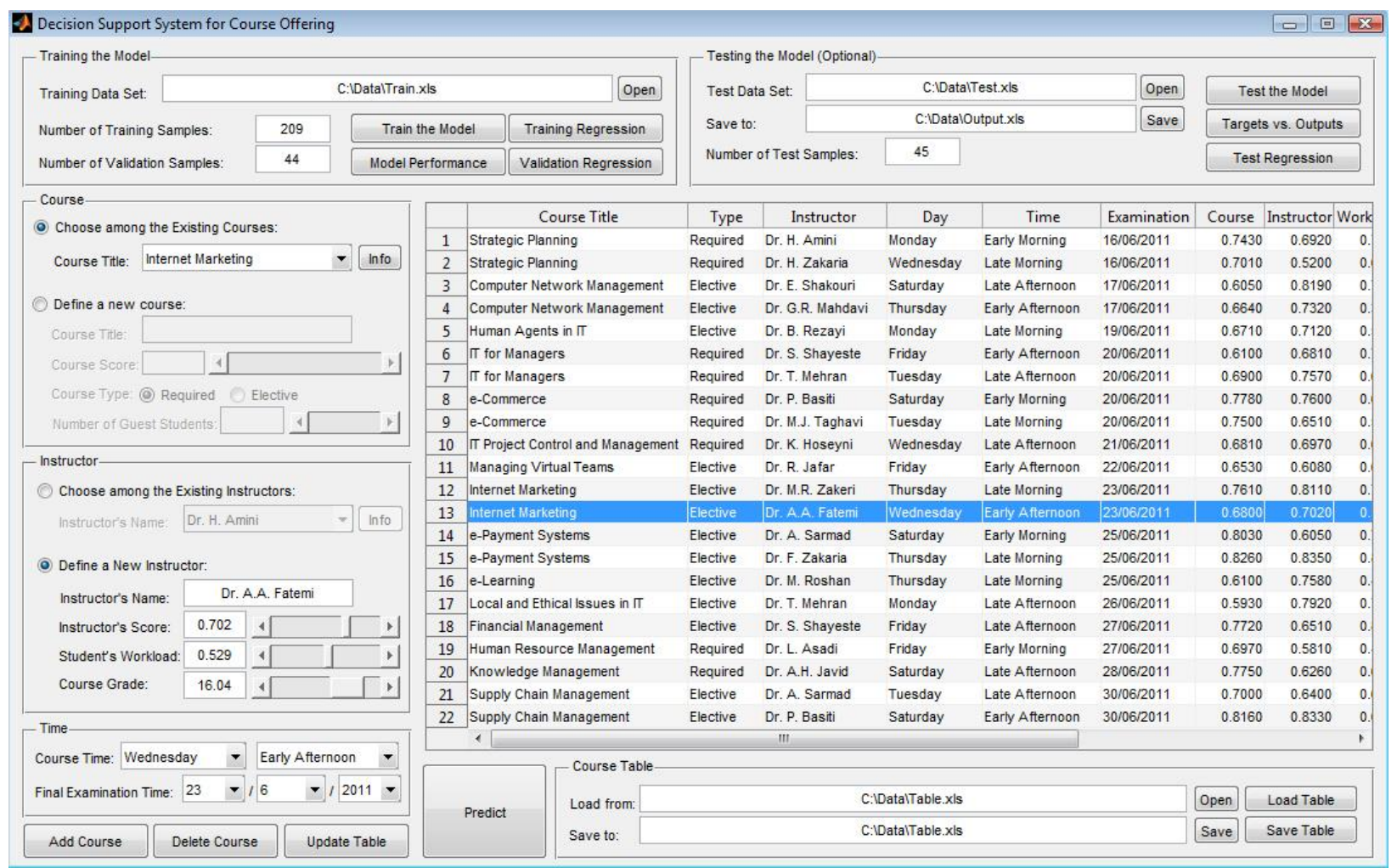

Fig. 7. The user interface of the proposed DSS

As illustrated in the figure, the administrator is readily able to interact with the model after its training (and optionally testing). He/she may either select a course among those previously taught or define a new one and its associated parameters. $\mathrm{He} / \mathrm{she}$ may also either choose a predefined instructor or invite a new one and set his/her parameters. The administrator can alter the course time as well as its final examination time to analyze their impacts on the number of registrations in the course after the drop and add period in the coming semester. Furthermore, the interface enables the administrator to change the uncontrollable variables to explore the student course selection behavior under various circumstances.

\subsection{Goal seeking}

Goal seeking computes the values of the inputs necessary to achieve a desired level of an objective ${ }^{47}$. It is the reverse of what-if analysis. For instance, in the course offering problem, the administrator may be interested to know, for a given specific number of registrations, which course should be offered, which instructor should teach the course, what class time is more appropriate, or what is the best final examination time. These sorts of questions cannot be handled through the proposed model and hence other ones must be developed. In this case the number of registrations is taken into account as an input for the model and one (or more) of preceding decision variables is considered as the output.

\section{Conclusion and Future Research}

In this contribution, the course offering problem was introduced as a complex and unstructured one which plays a critical role in student satisfaction with elearning. A DSS to support an administrator's decisions on this process was designed and implemented. The DSS was comprised of three main components: firstly, data came from 298 online graduate courses and was managed by Microsoft SQL Server 2008; secondly, a predictive model developed through MATLAB R2010b neural network toolbox; lastly, a graphical user interface implemented using MATLAB R2010b GUIDE. The model, as the core component of the DSS, was applied to imitate student course selection behavior. 
By conducting substantial investigations and thorough reviews of the relevant literature, 7 uncontrollable variables and 5 decision variables were identified as the inputs of the model. Its output was also the predicted number of registrations in a particular course after the drop and add period in the coming semester. To construct a model with high predictive ability, four regression techniques: SVR, NN, KNN, and DT were employed and their performance was compared with one another. Findings revealed that the NN model outperformed the others. Moreover, DT, KNN, and SVR models occupied the next positions, respectively. The results obtained from the models were compared with a traditional method as well. It was revealed that all the models are capable of producing more accurate prediction than the unintelligent method does. In this study, a three-layer perceptron neural network with 20 nodes in the hidden layer was trained and a MSE of 0.0014 and a correlation of 0.929 were achieved on the test data. This is an acceptable but not perfect prediction. The imperfection is due to some uncontrollable variables such as student personal preferences, which are either unknown, or their values are incomputable. Careless and dishonest, some student answers to the questions on the questionnaire are also another influential factor in producing imperfect prediction results. Finally, the obtained neural network model was utilized to conduct what-if analysis through the provided graphical user interface.

The proposed DSS has its limitations as well, which need further investigation. First the model can be extended to automatically detect the most satisfying courses for the upcoming semester, considering the existing constraints and thereby maximizing the total number of registrations and making profit for the corresponding institute. Second, although in this research neural network was experimentally detected as the best approach, using other machine learning methods or a hybrid one may lead to better prediction accuracy for other institutes. Considering this issue can specially aid those institutes that do not possess all past student registration data required for prediction. An example would be when the data related to student workload or course score is not available. Third, changing the structure of some variables or employing new ones may improve the efficacy of the method. For instance, considering more (or less) than four values for course time factors or an alternative formulation for final examination time may be more effective sometimes. Our future work will examine how to tackle these issues.

\section{References}

1. Babad E., Icekson T. and Yelinek Y., Antecedents and correlates of course cancellations in a university 'drop and add' period, Research in Higher Education, 49 (4) (2008), 293-316.

2. Babad E. and Tayeb A., Experimental analysis of students' course selection, British Journal of Educational Psychology, 73 (3) (2003), 373-393.

3. Babad E., Students' course selection: Differential considerations for first and last course, Research in Higher Education, 42 (4) (2001), 469-492.

4. Babad E., Darley J.M. and Kaplowitz H., Developmental aspects in students' course selection, Journal of Educational Psychology, 91 (1) (1999), 157-168.

5. Babcock P., Real costs on nominal grade inflation? New evidence from student course evaluations, Economic Inquiry, 48 (4) (2010), 983-996.

6. Boland M., Lehman E. and Stroade J., A comparison of curriculum baccalaureate degree programs in agribusiness, The International Food and Agribusiness Management Review, 4 (3) (2001), 225-35.

7. Bourne J. and Moore J.C., Elements of quality online education: practice and direction, Needham, MA: The Sloan Consortium, Vol. 4 (2003).

8. Baylari A. and Montazer Gh.A., Design a personalized e-learning system based on item response theory and artificial neural network approach, Expert Systems with Applications, 36 (4) (2009), 8013-8021.

9. Carswell A.D. and Venkatesh V., Learner outcomes in a distance education environment, International Journal of Human-Computer Studies, 56 (5) (2002), 475-494.

10. Centra, J.A., Will teachers receive higher student evaluations by giving higher grades and less course work?, Research in Higher Education, 44 (5) (2003), 495-518.

11. Chiu C.M., Sun S.Y., Sun P.C. and Ju T.L., An empirical analysis of the antecedents of web-based learning continuance, Computers \& Education, 49 (4) (2007), 1224-1245.

12. Chiu C.M., Hsu M.H., Sun S.Y., Lin T.C. and Sun P.C., Usability, quality, value and e-learning continuance decisions, Computers \& Education, 45 (4) (2005), 399-416.

13. Curry B. and Morgan P.H., Model selection in neural networks: Some difficulties, European Journal of Operational Research, 170 (2) (2006), 567-577.

14. Darby J.A., The effects of the elective or required status of courses on student evaluations, Journal of 
Vocational Education and Training, 58 (1) (2006), 1929.

15. Davison E. and Price J., How do we rate? An evaluation of online student evaluations, Assessment \& Evaluation in Higher Education, 34 (1) (2009), 5165.

16. Elliott K. and Shin D., Student satisfaction: an alternative approach to assessing this important concept, Journal of Higher Education Policy \& Management, 24 (2) (2002), 197-209.

17. Ellis R.A., Ginns P. and Piggott L., E-learning in higher education: Some key aspects and their relationship to approaches to study, Higher Education Research \& Development, 28 (3) (2009), 303-318.

18. Entwistle N.J. and Ramsden P., Understanding student learning, London: Croom Helm, (1983).

19. Frias-Martinez E., Chen S.Y. and Liu X., Automatic cognitive style identification of digital library users for personalization, Journal of the American Society for Information Science and Technology, 58 (2) (2007), 237-251.

20. Greenwald A.G. and Gillmore G.M., No pain, no gain? The importance of measuring course workload in student rating of instruction, Journal of Educational Psychology, 89 (4) (1997), 743-751.

21. Gorry G.A. and Scott-Morton M.S., A framework for management information systems, Sloan Management Review, 13 (1) (1971), 55-70.

22. Hagan M.T., Demuth H.B. and Beale M.H., Neural network design, Boston: PWS Publishing, (1996).

23. Hagan M.T. and Menhaj M., Training feedforward networks with the Marquardt algorithm, IEEE Transactions on Neural Networks, 5 (6) (1994), 989 993.

24. Hien N.T.N. and Haddaw P., A decision support system for evaluating international student applications, 37th ASEE/IEEE Frontiers in Education Conference, Milwaukee, WI, (2007), 1-6.

25. Hornik K., Stinchcomb M. and White H., Multilayer feedforward networks are universal approximators, Neural Networks, 2 (5) (1989), 359-366.

26. Jeong H.Y., Choi C.R. and Song Y.J., Personalized learning course planner with e-learning DSS using user profile, Expert Systems with Applications, 39 (3) (2012), 2567-2577.

27. Johnson R.D., Hornik S. and Salas E., An empirical examination of factors contributing to the creation of successful e-learning environments, International Journal of Human-Computer Studies, 66 (5) (2008), 356-369.

28. Jovanovic M., Vukicevic M., Milovanovic M. and Minovic M., Using data mining on student behavior and cognitive style data for improving e-learning systems: a case study, International Journal of Computational Intelligence Systems, 5 (3) (2012), 597-610.

29. Kotsiantis S.B., Use of machine learning techniques for educational proposes: a decision support system for forecasting students' grades, Artificial Intelligence Review 37 (4) (2012), 331-344.

30. Lee J.W., Online support service quality, online learning acceptance, and student satisfaction, The Internet and Higher Education, 13 (4) (2010), 277283.

31. Lee B.C., Yoon J.O. and Lee I., Learners' acceptance of e-learning in South Korea: Theories and results, Computers \& Education, 53 (4) (2009), 1320-1329.

32. Levy Y., Comparing dropouts and persistence in elearning courses, Computers \& Education, 48 (2) (2007), 185-204.

33. Li K.F.R. and Chen J.S., Prediction and assessment of student learning outcomes in calculus, $3 \mathrm{rd}$ International Conference on Computer Research and Development, IEEE, Shanghai, (2011), 299-303.

34. Lim C.K., Computer self-efficacy, academic selfconcept, and other predictors of satisfaction and future participation of adult distance learners, The American Journal of Distance Education, 15 (2) (2001), 41-51.

35. Lo J.J., Chan Y.C. and Yeh S.W., Designing an adaptive web-based learning system based on students' cognitive styles identified online, Computers \& Education, 58 (1) (2012), 209-222.

36. Lykourentzou L., Giannoukos L., Mpardis G., Nikolopoulos V. and Loumos V., Early and dynamic student achievement prediction in e-learning courses using neural networks, Journal of the American Society for Information Science and Technology, 60 (2) (2009), 372-380.

37. Marquardt D.W., An algorithm for least-squares estimation of non-linear parameters, Journal of the Society for Industrial and Applied Mathematics, 11 (2) (1963), 431-441.

38. Marsh H. and Roche L., Effects of grading leniency and low workload on students' evaluations of teaching: Popular myth, bias, validity, or innocent bystanders?, Journal of Educational Psychology, 92 (1) (2000), 202-228.

39. McGoldrick K. and Schuhmann P.W., Instructor gender and student registration: An analysis of preferences, Education Economics, 10 (3) (2002), 241-260.

40. Paechter M., Maier B. and Macher D., Students' expectations of, and experiences in e-learning: Their relation to learning achievements and course satisfaction, Computers \& Education, 54 (1) (2010), 222-229.

41. Rumelhart D.E., Hinton G.E. and Williams R.J., Learning representations by back-propagating errors, Nature, 323 (9) (1986), 533-536.

42. Schwitzer A., Ancis J. and Brown N., Promoting student learning and student development at a distance: Student affairs principles and practices for televised instruction and other forms of distance learning (2nd Ed.), Lanham, MD: American College Personnel Association: University Press of America, (2001). 
43. Steffes E.M. and Burgee, L.E., Social ties and online word of mouth, Internet Research, 19 (1) (2009), 4259.

44. Sun P.C., Tsai R.J., Finger G., Chen Y.Y. and Yeh D., What drives a successful e-Learning? An empirical investigation of the critical factors influencing learner satisfaction, Computers \& Education, 50 (4) (2008), 1183-1202.

45. Sun Y., Peng Y., Chen Y. and Shukla A.J., Application of artificial neural networks in the design of controlled release drug delivery systems, Advanced Drug Delivery Reviews, 55 (9) (2003), 1201-1215.

46. Svanum S. and Aigner C., The influences of course effort, mastery and performance goals, grade expectancies, and earned course grades on student ratings of course satisfaction, British Journal of Educational Psychology, 81 (4) (2011), 667-679.

47. Turban E., Sharda R. and Delen D., Decision support and business intelligence systems, 9th Edition, New Jersey: Prentice Hall, (2010).

48. Villaverde J.E., Godoy D. and Amandi A., Learning styles' recognition in e-learning environments with feed-forward neural networks, Journal of Computer Assisted Learning, 22 (3) (2006), 197-206.

49. White H., Some asymptotic results for learning in single hidden layer feedforward network models, Journal of the American Statistical Association, 84 (408) (1989), $1003-1013$.

50. Yukselturk E. and Yildirim Z., Investigation of interaction, online support, course structure and flexibility as the contributing factors to students' satisfaction in an online certificate program, Educational Technology \& Society, 11 (4) (2008), 5165.

51. Zorrilla M., Garcia D. and Alvarez E., A decision support system to improve e-learning environments, Proceedings of the 2010 EDBT/ICDT Workshops, ACM, Lausanne, Switzerland, (2010), 22-26.

\section{About the Authors}

Ahmad A. Kardan received his B.S. in Electrical Engineering from Sharif University of Technology (1976-Iran), his M.Sc. in Digital Systems from the Brunel University (1997-UK), and his PhD. in BioElectric Engineering from Imperial College of Science and Technology (2001-UK). He founded ELearning Center of Amirkabir University of Technology in 2000 and managed the center till 2004. He is currently a faculty member of the Computer Engineering Department, at Amirkabir University of Technology, Tehran, Iran. He teaches graduate courses in computing and information technology with emphasis on advanced e-learning and distributed educational systems. Dr. Kardan is involved in researches in Intelligent Tutoring Systems (ITS), Learning Advisory Systems, Adaptive Learning, Learner Modeling, Concept Mapping, Collaborative Learning, Annotation Processing, and Applying Data Discovery in e-Learning. He has presented more than 80 papers at national and international conferences, journals and as chapters for related books. Dr. Kardan can be contacted at: aakardan@aut.ac.ir

Hamid Sadeghi is a Ph.D. candidate in IT engineering at Amirkabir University of Technology, Tehran, Iran. He is also a faculty member of the Department of Computer Engineering at Hashtgerd Branch, Islamic Azad University, Alborz, Iran. His main research interests include decision support systems, data mining and machine learning, eLearning technologies, computer-supported collaborative learning (CSCL), optimization methods, Web information retrieval, metasearch engine designing, search engines and metasearch engines performance evaluation, Web search technology and aggregation operators. Hamid Sadeghi can be contacted at: hisadeghi@gmail.com 